\title{
Sub-surface diagnosis for tantalite in Iseyin SW, Nigeria using magnetic survey method
}

\author{
Ikusika $\mathrm{A}^{1^{*}}$, Popoola O.I ${ }^{2}$ \\ ${ }^{1}$ Adeyemi College of Education, Ondo \\ ${ }^{2}$ University of Ibadan, Ibadan. \\ *Corresponding author E-mail: akintayodavies@yahoo.com
}

\begin{abstract}
A magnetic survey was carried out at a site in Iseyin, Oyo state. The study delineates possible structures that may favour the accumulation of tantalite, a magnetic mineral. A ground based technique was employed using proton precision magnetometer G-856 AX to deduce subsurface lithology and structure that may indirectly aid the identification of mineralized rocks. A total of ten geophysical traverses were established in W-E direction in the study area. The acquired magnetic field data were corrected for drift. Qualitative and quantitative interpretations were adopted to obtain the negative peak value and the maximum positive peak value. The contour maps, image maps and the 1-grid maps present the sub-surface picture of the geological structures that are assumed to habour the metallic minerals. The study area is underlain by a rock unit of accumulated minerals. The overburden is relatively thin within the study area and the metallic minerals are in disseminated quantity and at a shallow depth.
\end{abstract}

Keywords: Drift, magnetic field data, metallic mineral, peak value, Tantalite.

\section{Introduction}

Geophysical investigation is commonly used in engineering site investigation, mineral exploration and ground water investigation. Its relevance is in depth to the basement rock determination, structural mapping, lithologic boundary differentiation. [1-8]. However, geophysical investigation is important in mapping buried steel drums, tanks, pipelines [9]. This work was aimed at carrying magnetic survey of the study area and to investigate sub-surface geology on the basis of anomalies in Earth's magnetic field resulting from magnetic properties of the underlying rock delineates ores that present magnetic anomalies and correlate the matching of anomalies with the possible magnetic sources.

\section{Geological setting}

The study area has a latitude $\mathrm{N} 7^{0} 58^{\mathrm{I}}$ and longitude $\mathrm{E} 3^{0} 36^{\mathrm{I}}$ with elevation variation between $293 \mathrm{~m}-317 \mathrm{~m}$ and lies within the basement complex of southwestern Nigeria which characterized by migmatite gneiss. The local geological mapping of the study area revealed the area is underlain mainly by a rock unit, granite gneiss. The rock are generally trending in Northwest - Southeast direction and dipping to the west. All the exposed outcrops observed have low fracture, indication minor evidence of deformation. The megamasopic minerals observed in this rock type include quartz, feldspar and biotite [15] 


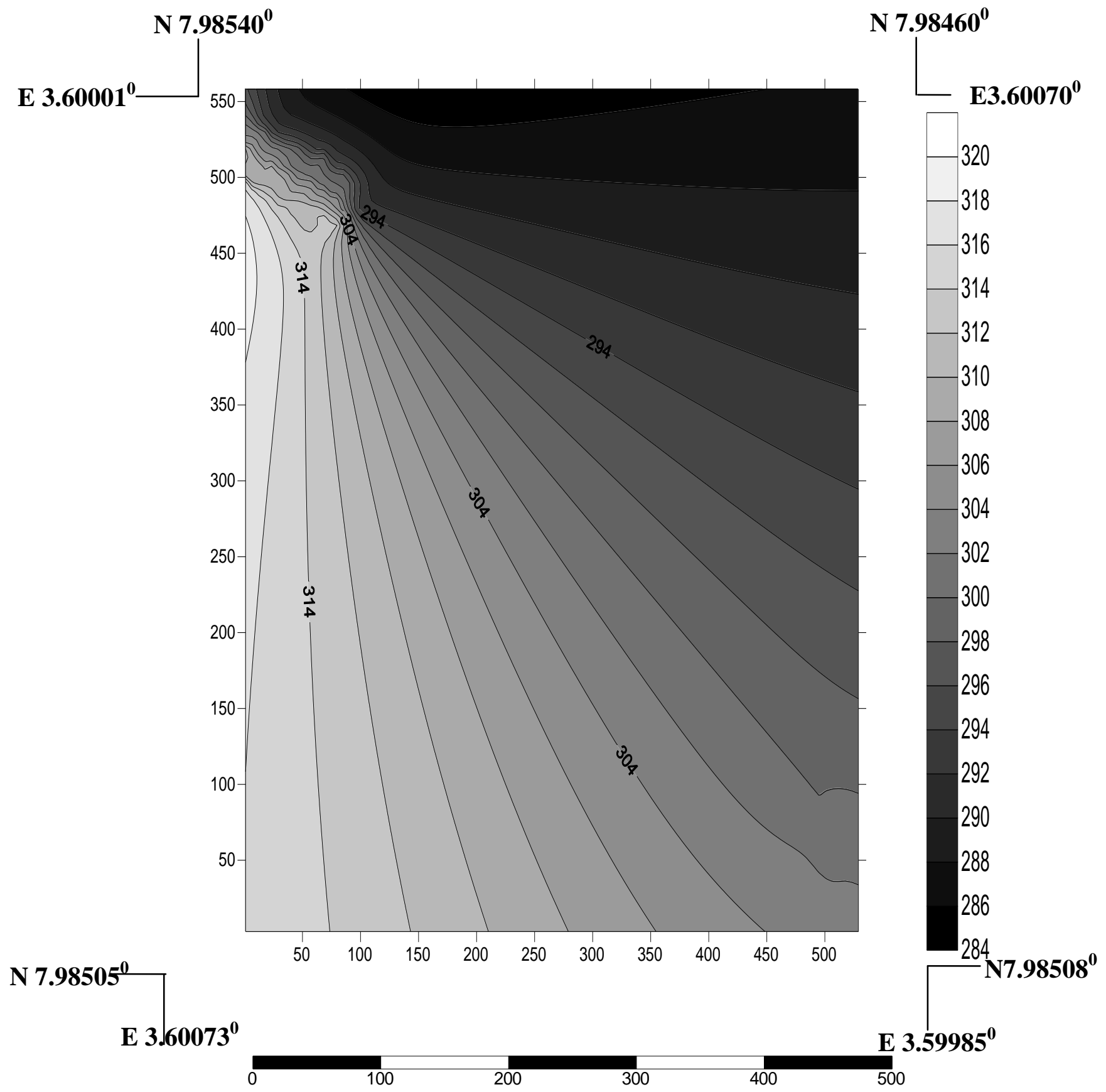

\subsection{Theory of magnetic method}

Earth's magnetic field is generated in the fluid outer core by a self - exciting dynamo process. When this liquid outer core cools due to material becoming denser, it sinks towards the inside of the outer core leaving a new liquid matter to the outside and thus convectional currents are generated. The electric currents flowing in the slowly moving molten iron generates the magnetic field [11]. In addition to sources in Earth's core, the magnetic field observable at the planet's surface has sources in the crust and in the ionosphere and magnetosphere. The geomagnetic field varies on a range of scales and a description of these variations is now made-ordered from low to high frequency variations in both space and time [16]. The field, as measured by a magnetic sensor or above the earth's surface is a composite of several magnetic fields generated by a variety of sources [10-18]. The fields are superimposed on each other and through inductive processes interact with each other. The most important of these geomagnetic sources are:

a. the main fi0eld generated in Earth's conducting, fluid outer core $\left(\mathbf{B}_{\mathrm{m}}\right)$;

b. the crustal field from Earth's crust/upper mantle $\left(\mathbf{B}_{\mathrm{c}}\right)$; 
c. the combined disturbance field from electrical currents flowing in the upper atmosphere and magnetosphere, which also induce electrical currents in the sea and the ground $\left(\mathbf{B}_{\mathrm{d}}\right)$ Thus, the observed magnetic field is a sum of contributions

$\mathbf{B}(\boldsymbol{r}, t)=\mathbf{B}_{\mathrm{m}}(\boldsymbol{r}, t)+\mathbf{B}_{\mathrm{c}}(\boldsymbol{r})+\mathbf{B}_{\mathrm{d}}(\boldsymbol{r}, t)$

Common magnets exhibit a pair of poles and are therefore referred to as dipoles. The magnetic moment $\mathbf{M}$ of a dipole with poles of strength $\mathbf{m}$ a distance $\mathbf{l}$ apart is given by

$\mathrm{M}=\mathrm{ml}$

The intensity of induced magnetization $\mathbf{J}_{\mathbf{i}}$ of a material is defined as the dipole moment per unit volume of material. $\mathrm{J}_{\mathrm{i}=\mathrm{M} / \mathrm{LA}}$

Rock types vary in magnetic susceptibilities $\mathbf{J}=\mathbf{k H}$, where $\mathrm{k}$ is the magnetic susceptibility [17].

\subsection{Methodology}

Ten magnetic survey traverses were made. Magnetic measurement was made with portable proton magnetometer G$856 \mathrm{AX}$, executed over the established traverses covering enough segment of the entire area. Data collected was corrected to remove all contributions to the observed magnetic field other than those caused by sub-surface magnetic sources using trend analysis. The data was presented as profiles and contours. The contours maps, image maps and the 1-grid vector maps were used to present the subsurface picture of the geological structures that are assumed to habour the metallic minerals through the bulky unit of magnetic field and the action of the field towards concentrated sources.

Table 1: Observed magnetic field Profile 1

\begin{tabular}{cccc}
\hline $\mathrm{X}$ & $\mathrm{Y}$ & Reading $(\mathrm{nT})$ & Line \\
\hline 0.000 & 100.000 & 32927.400 & 1 \\
0.000 & 90.000 & 32931.100 & 1 \\
0.000 & 80.000 & 32923.000 & 1 \\
0.000 & 70.000 & 32921.000 & 1 \\
0.000 & 60.000 & 32921.100 & 1 \\
0.000 & 50.000 & 32913.800 & 1 \\
0.000 & 40.000 & 32918.000 & 1 \\
0.000 & 30.000 & 32917.600 & 1 \\
0.000 & 20.000 & 32916.100 & 1 \\
0.000 & 10.000 & 32915.300 & 1 \\
0.000 & 0.000 & 32915.800 & Line \\
\hline & & & 2 \\
\hline $\mathrm{X}$ & Table $2:$ Observed magnetic field Profile 2 & 2 \\
\hline 5.000 & $\mathrm{Y}$ & Reading $(\mathrm{nT})$ & 2 \\
5.000 & 10.000 & 32933.500 & 2 \\
5.000 & 20.000 & 32933.300 & 2 \\
5.000 & 30.000 & 32930.400 & 2 \\
5.000 & 40.000 & 32929.500 & 2 \\
5.000 & 50.000 & 32929.000 & 2 \\
& 60.000 & 32929.100 & 2 \\
\end{tabular}

\section{Discussion of result}

Qualitative and quantitative interpretations of the ground magnetic map and magnetic profiles which were used to obtain useful information on the probable depth to the magnetic body. For the quantitative analysis, the depth to basement was calculated using Peter's half slope method after it was corrected for the purpose of removing contributing factor (Noise) other than the observed magnetic field to determine the depth extent and size. Both qualitative and quantitative results were compared and the conclusion was drawn. 


\section{Profile1}

Fig. 1.2 shows the variation in the sub-surface magnetic intensity. The anomaly source is sharp. The shaper the anomaly is, the faster it falls from its maximum value and the shallower the source. The wavelength of the anomaly in fig 1.1 is short and has a positive and negative amplitude which shows it is a near surface feature and an indicative of intensity of magnetization and that zone is a zone of mineralization. The image map and the 1-grid vector map display the image of the bulk of unit of the magnetic field and the action of the field towards the point where there is high magnetic field intensity.

Longitude (degree)

\section{PROFILE 1}
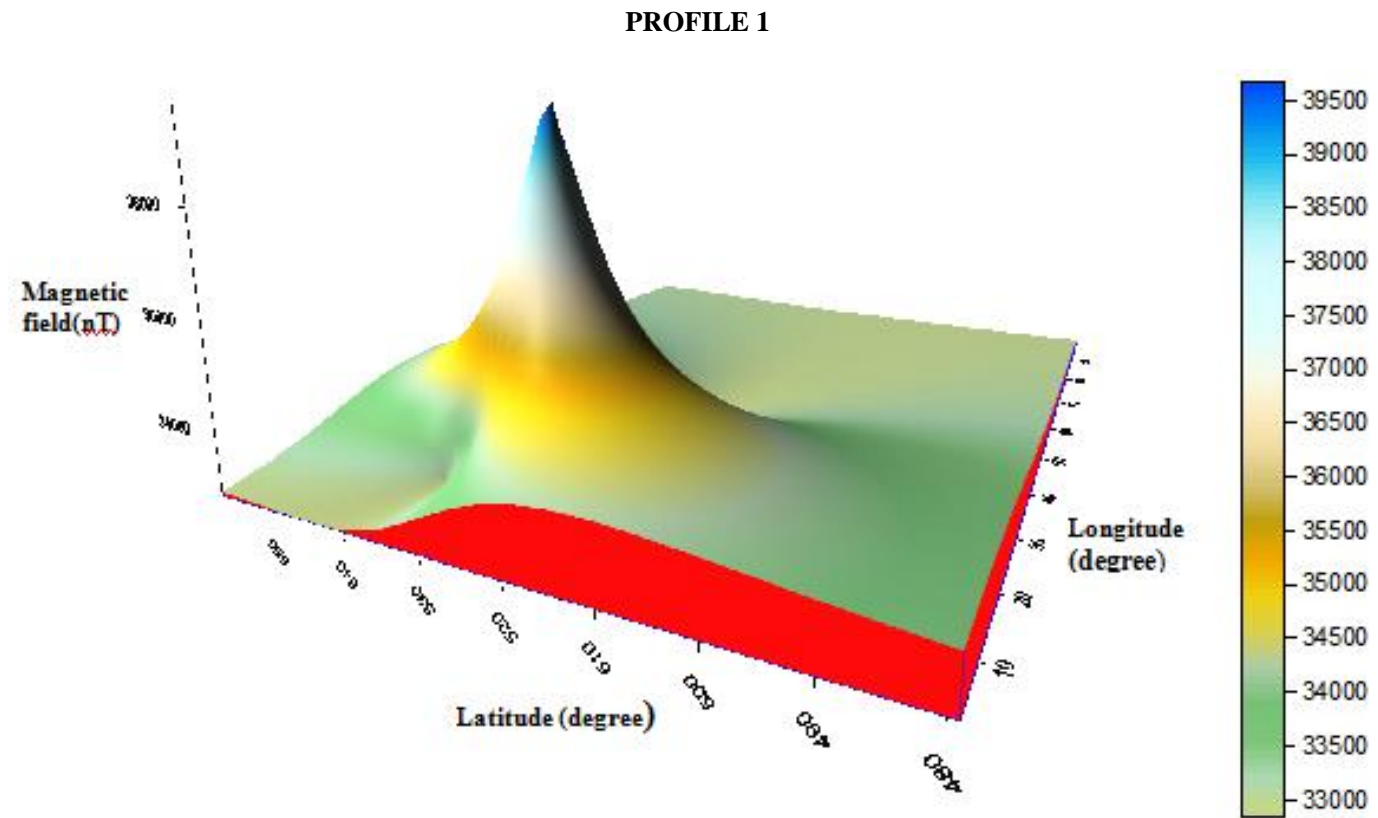

Fig. 1.2: 3D surface Magnetic Field of Profile 1

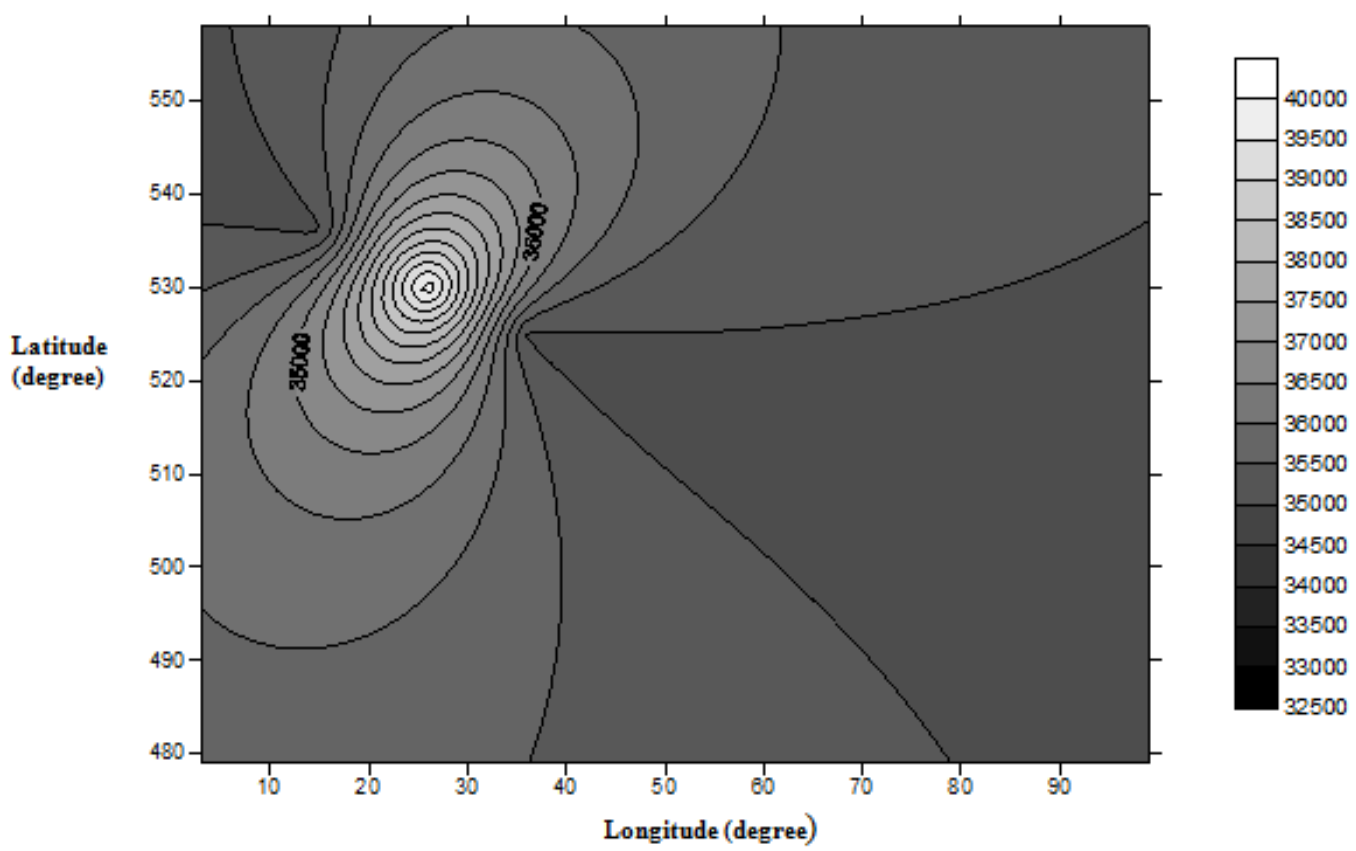

Fig.1.3: Contour Map of Magnetic Field of Profile 1 


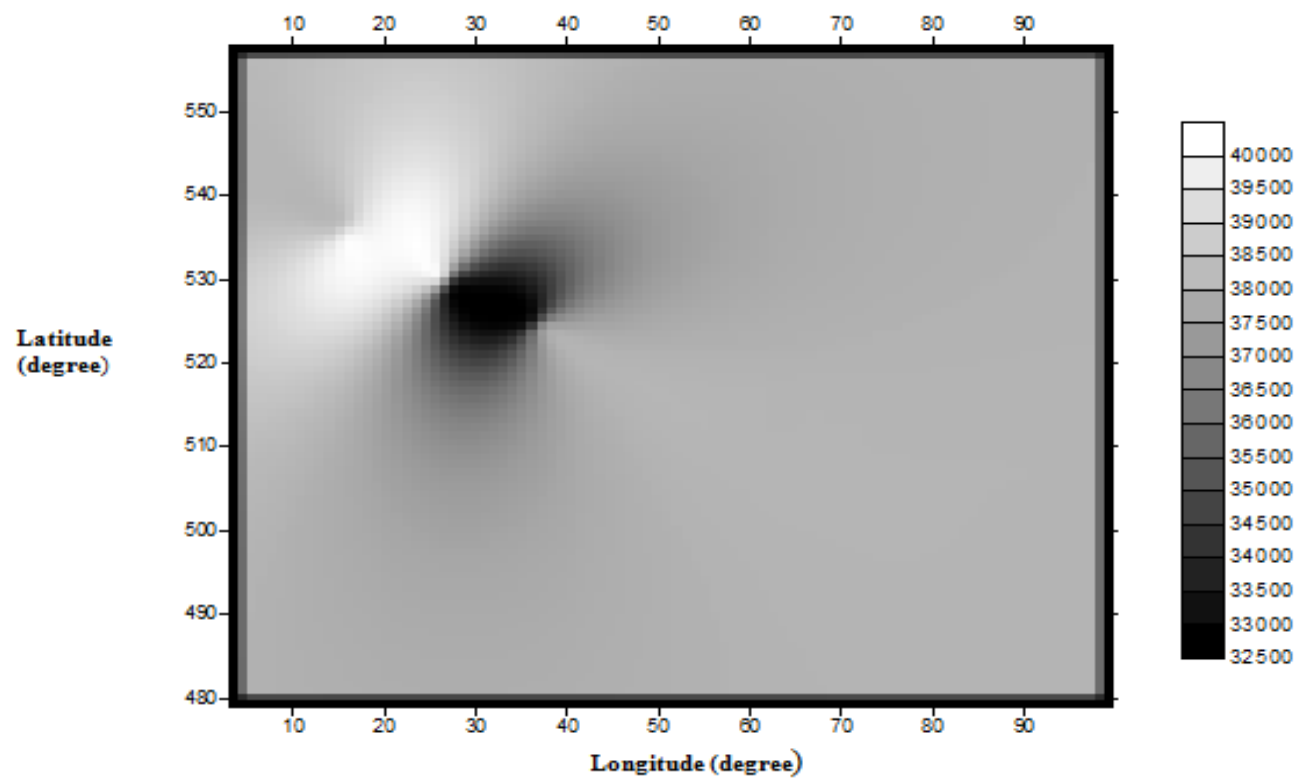

Fig. 1.4: Image Map of Magnetic Field of Profile 1

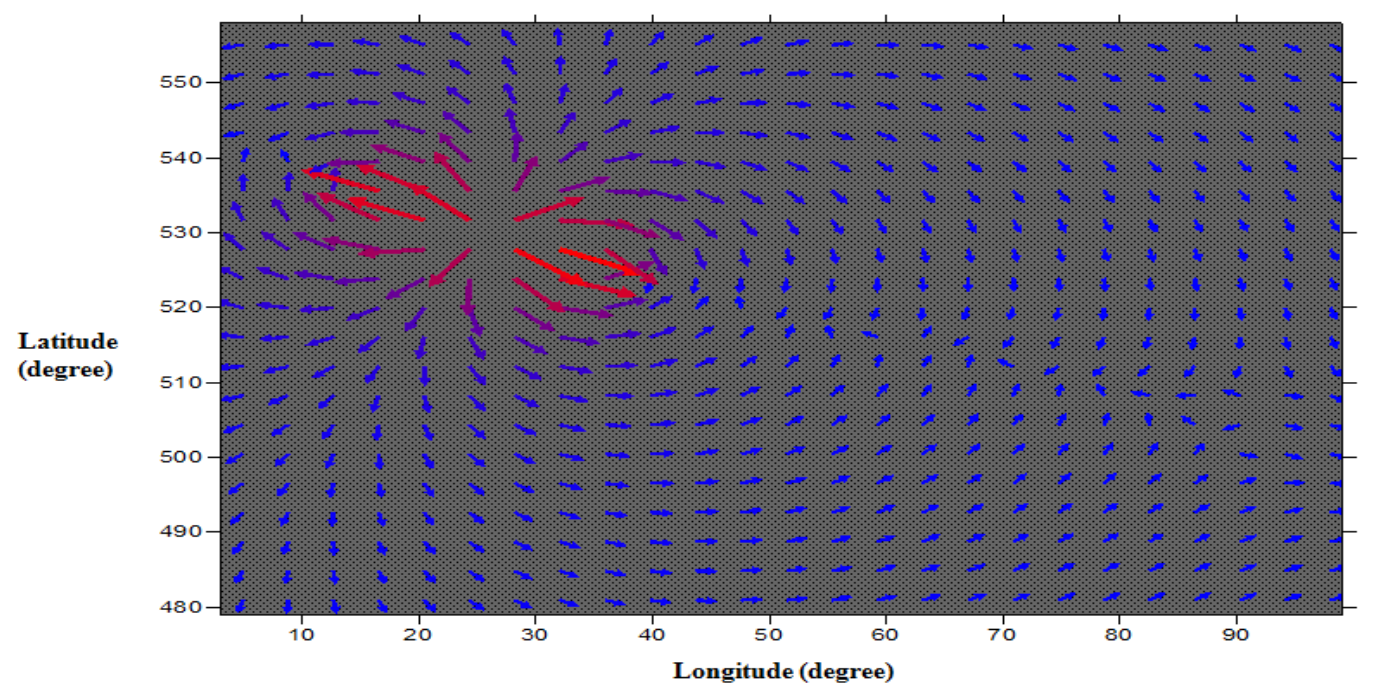

Fig. 1.5: 1 - Grid Vector Map of Magnetic Field of Profile 1

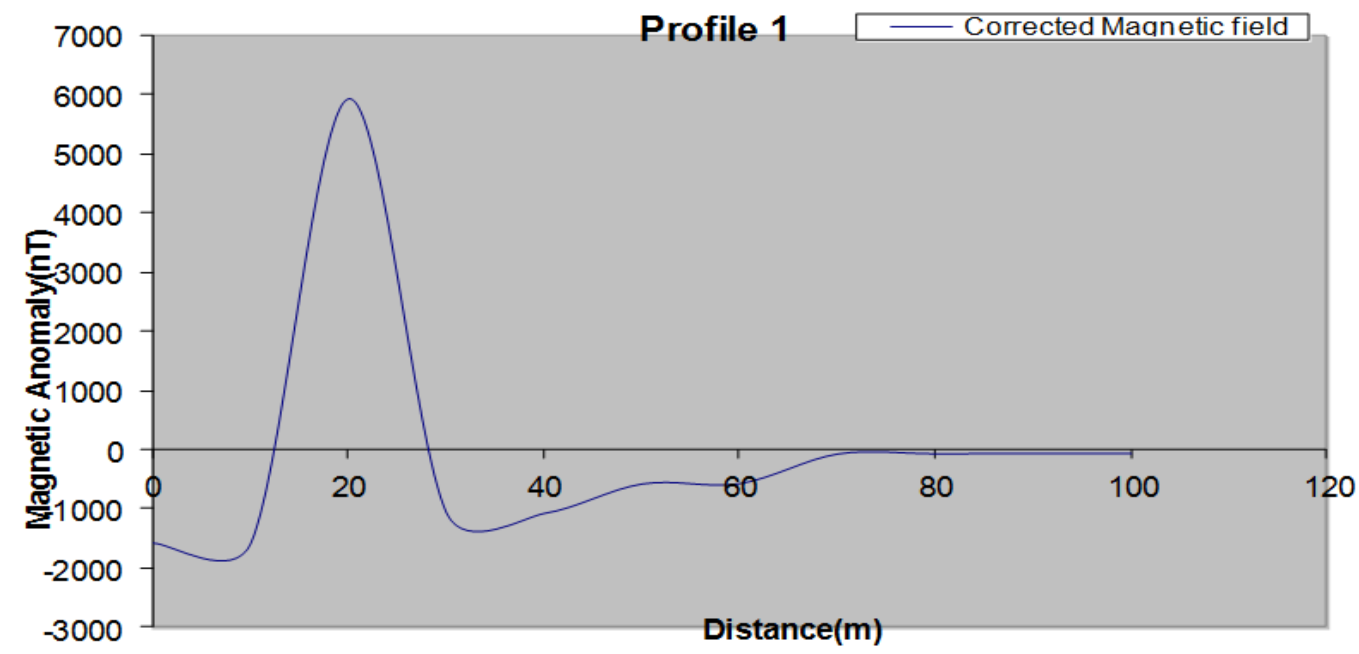

Fig. 1.6: Corrected Magnetic Field of Profile 1 


\section{Profile 2}

The contour map in figure 2.2 shows the field being moved towards the same point where there is large and high magnetic field and the broadening of the contour is an indicative of the downthrow of magnetic rocks. The image map in figure 2.3 displays the image of the bulk of the unit of the magnetic field and figure 2.4 represents the action of the field towards the point where there is high magnetic field intensity. In figure 2.5 , the positive and negative amplitude (but less pronounced in the positive amplitude) indicate low intensity of magnetization and the little variations which are the magnetically quiet segments has low susceptibility and the magnetically noisy segment has moderate-high susceptibility rocks near surface.

PROFILE 2
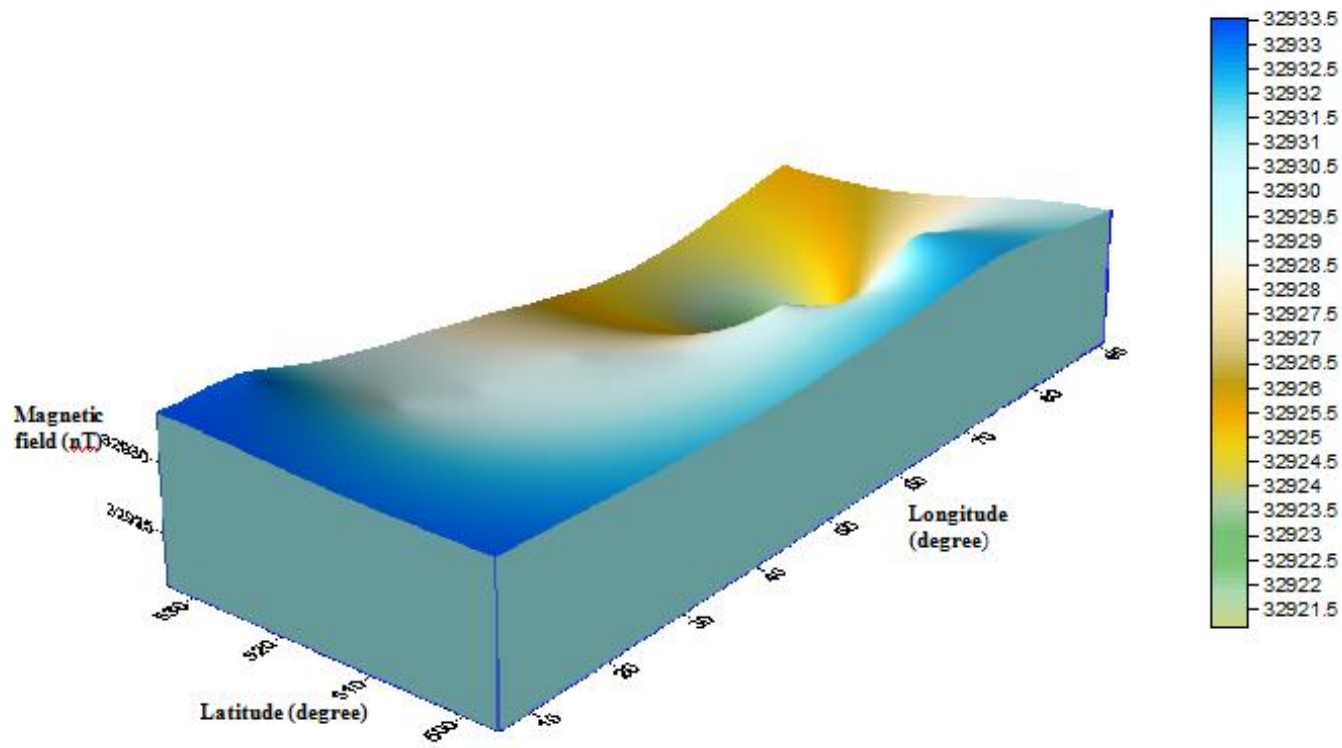

Fig. 2.1: 3D surface Magnetic Field of Profile 2

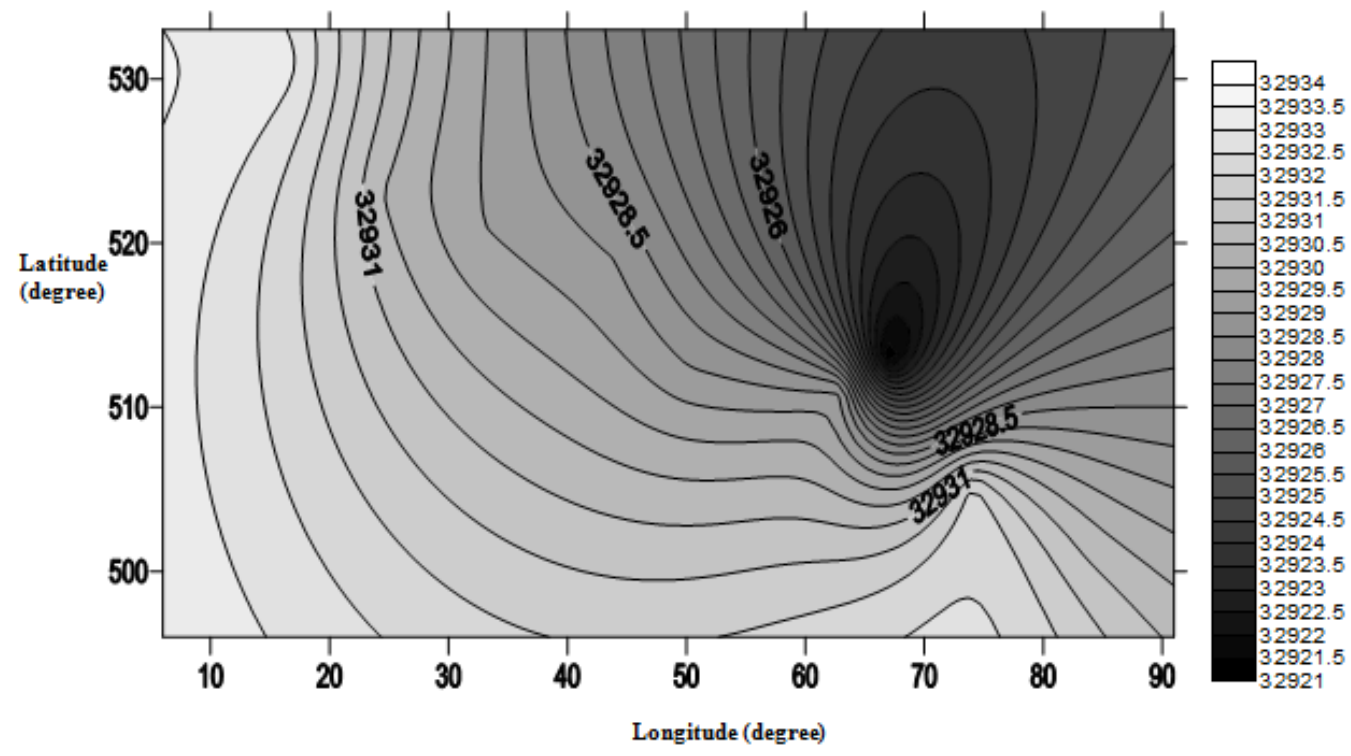

Fig. 2.2: Contour Map of Magnetic Field of Profile 2 


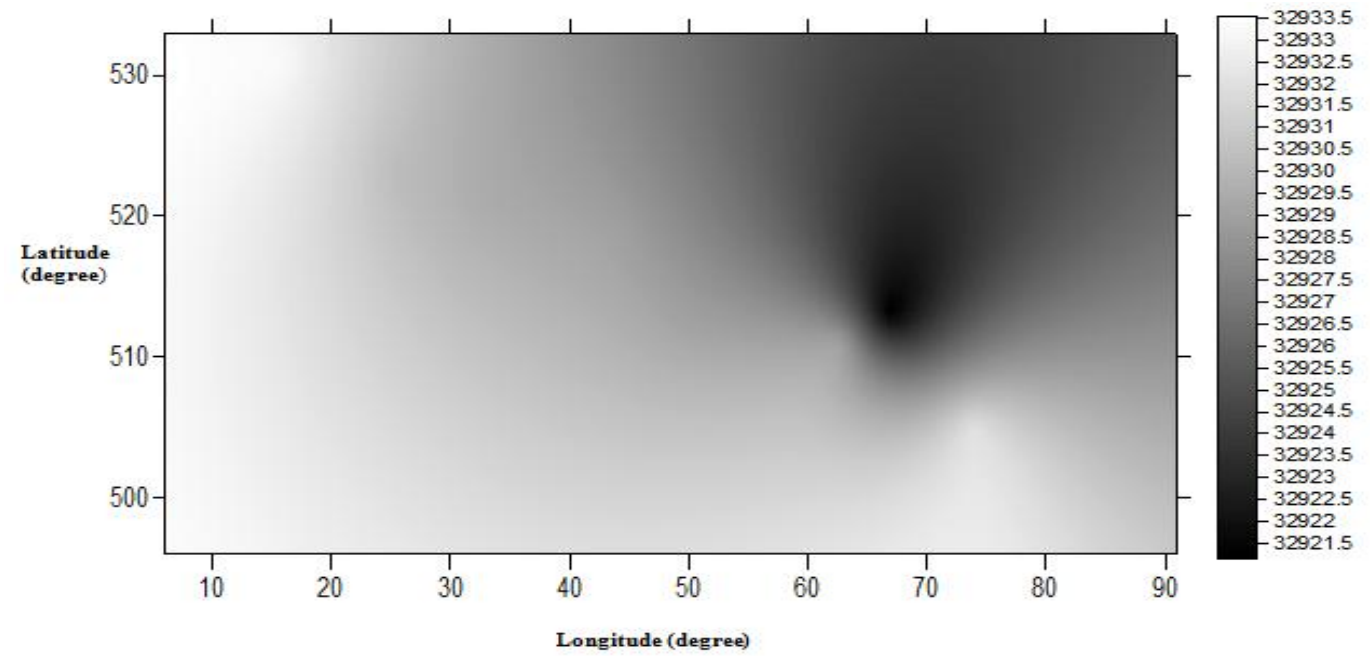

Figure 2.3: Image Map of Magnetic Field of Profile 2

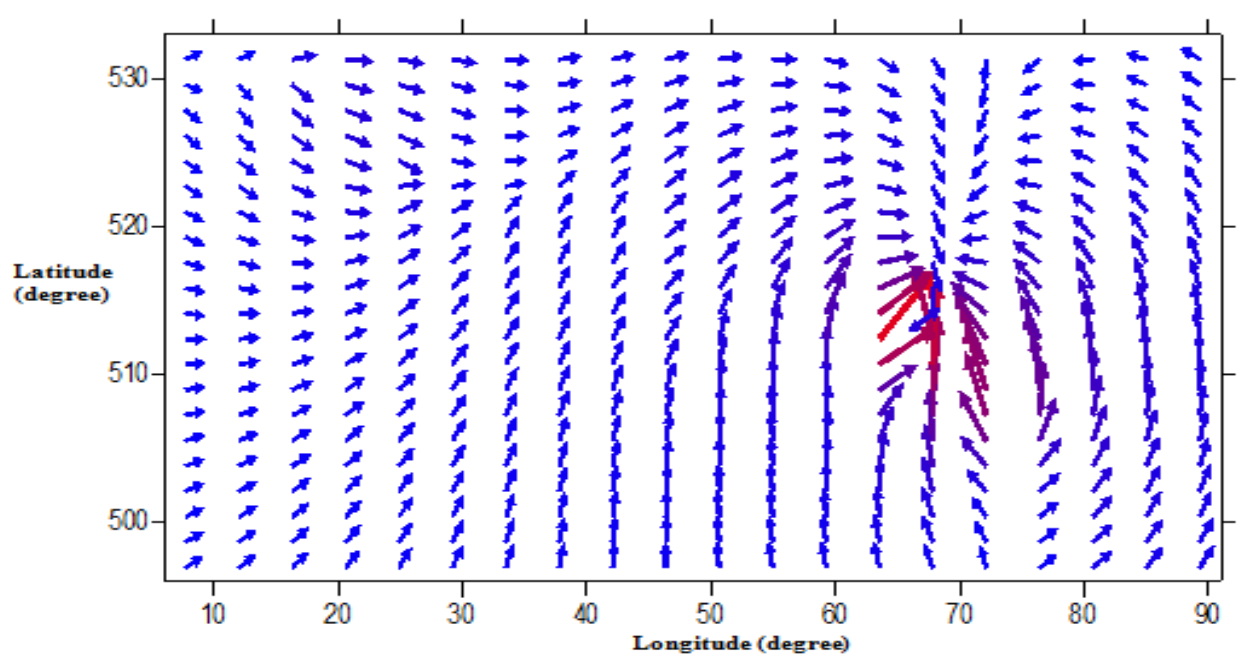

Fig. 2.4: 1- Grid Vector Map of Magnetic Field of Profile 2

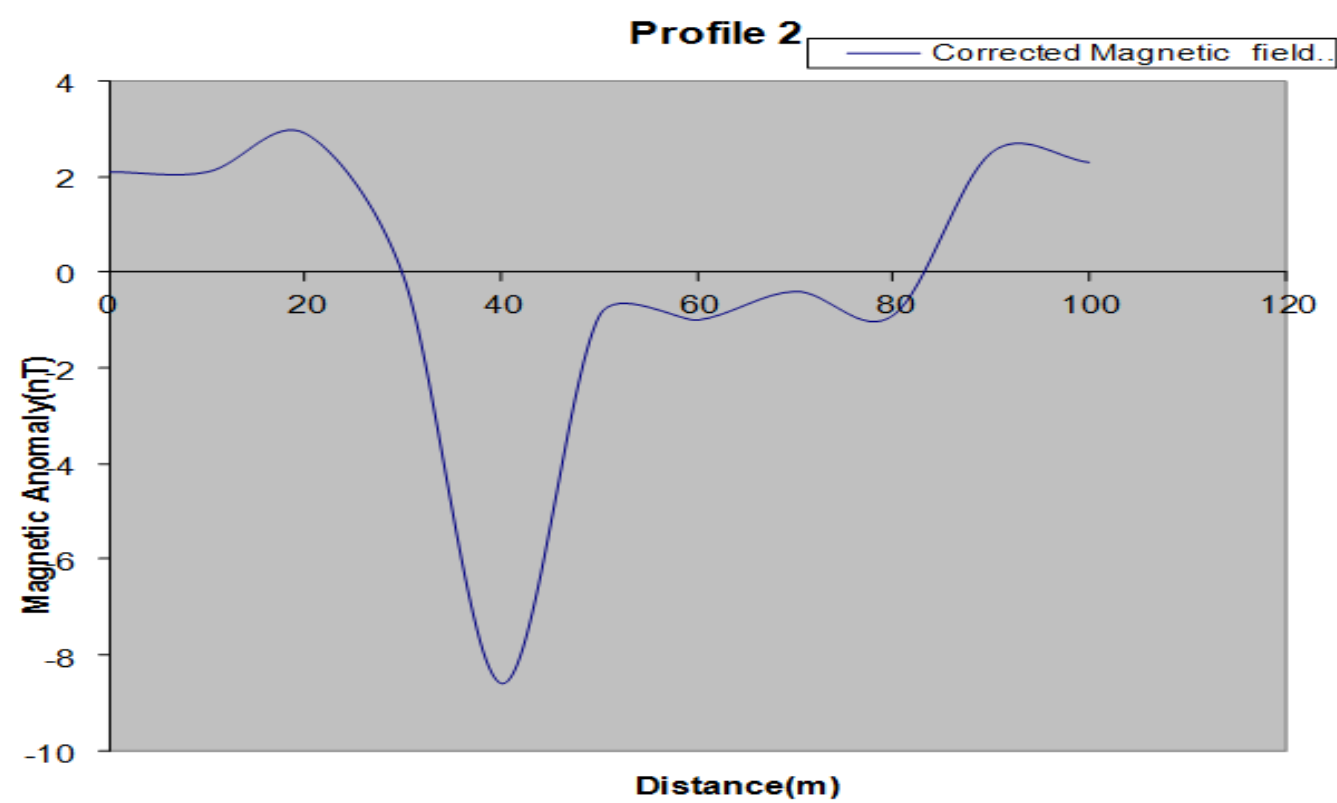

Fig. 2.5: Corrected Magnetic Field of Profile 2 


\section{Conclusion}

Base on the results of magnetic survey carried out, the magnetic section presents pictures of various geological structures that are assumed to habour the magnetic minerals. The interpretation provided helps to have picture of sub-surface characteristics. The nature of the anomalies in this area suggests that the rocks are bounded and offset by faults, fractures or discontinuities [19-20]. From the thickness and depth extent of the structures, it can be said that these structures are zones of metallic minerals (tantalite) in disseminated quantity (thin or dispersed quantity) and at near surface.

However, many geophysical methods commonly used in exploration have potential application to geoenvironmental investigation [9-11] therefore geophysicist should endeavor to integrate different geophysical methods that are relevant to investigations to delineate the true picture of the subsurface and also minerals should be taken to the laboratory for chemical analysis so as to ascertain the type of minerals.

\section{Acknowledgements}

We appreciate the effort of Mr. Adebisi and all friends who assisted us in different capacities during the acquisition of the data used for this study.

\section{References}

[1] B.W Bevan. "The magnetic anomaly over a Brick foundation". Archeology prospecting Vol. 1 (1994) pp. 93-104

[2] R.Chevallier, S.Mathieu.“Susceptibilité magéntique spécifique de pyroxenes monocliniques”: Bull. Soc. chim. Fr., No.5, (1958) pp.726729.

[3] J.A Dearing, P.M. Bird, R.J.L. Dann, and S.F. Benjamin,. "Secondary Ferrimagnetic Minerals in Welsh soils: A comparison of mineral magnetic detection methods and implications for mineral formation", Geophysics Journal International, Vol.130 (1997), Pgs 727-736.

[4] A.M.J. Deswart. "The Geology of the country around Ilesa. Geology Survey". Nigeria Bulletin, (1953) Pgs 23 -55.

[5] A.A Elueze. Petrology and Gold mineralization of the Amphibolites belt. Ilesha area southwestern Nigeria. Geol. En.Mijbouw 65: (1986) pp.189-195.

[6] J.K. Eyre. Frequency-dependence of Magnetic Susceptibility for population of single domain grains, geophysics Journal International Vol. 129 (1997) pp. 209-211.

[7] S. L. Folami. "Interpretation of Aeromagnetic anomalies in Iwaraya area, SW, Nigeria". J. Min. Geol. 28(2): (1992) pp.291-396.

[8] J .Jensen, and A.R. Mackintosh. Rare Earth Magnetism: Structures and Excitations, Clarendon Press Oxford, (1991)

[9] J. S. Kayode. "Ground magnetic study of Jeda-Iloko Area, SW,Nigeria and Its Geologic Implications". M.Tech Thesis Fed. Univ. of Technology, Akure, Nigeria.(2006).

[10] B.A. Maher. "Magnetic Properties of some Synthetic sub-micron Magnetites". Geophysics Journal Vol 94, (1998) pp. 83-93.

[11] L.L. Nettledon. Gravity and Magnetism in Oil prospecting. McGraw Hill, NY. (1976)

[12] C.O. Ofoegbu, and N.L. Mohan. "Interpretation of Aeormagnetic anomalies over part of Southeastern Nigeria using three- dimension Hilbert transformation". Pure and Applied Geophyscis, vol 134, (1990) pp. 13-29.

[13] Olayinka IA, Oyedele AA (2001). Geoelectrical investigation of sites along the proposed Ibadan-llorin dual carriageway. J. Min. Geol. 57(2):163-175

[14] M.O. Olorunfemi and E.T.Okhue. "Hydrogeology and geologic significance of a geoelectric survey at Ile-Ife Nigeria" Nig.Journal of Mining and Geology, Vol.28, (1992) pp.225

[15] M.A. Rahaman. Review of the basement geology of SW Nigeria in Kogbe C.A(Ed) Geology of Nigeria. Elizabeth Pub. Co. Lagos (1976) pp. 41-58.

[16] R.L. Reynolds, J.G. Rosenbaum, M.R. Hudson, and N.S. Fishman. "Rock magnetism, the distribution of magnetic minerals in the Earth's crust, and aeromagnetic anomalies, in Hanna", W.F., ed., Geologic Application of Modern Aeromagnetic surveys: U.S. geological Survey Bulletin 1924, (1990) pp. 24-45.

[17] C.Richter, and B.A. Van der Pluijm,. "Separation of paramagnetic and ferromagnetic susceptibilities using low temperature magnetic susceptibilities and comparison with high field methods", Physics of the Earth and Planetary Interiors Vol. 82, (1994) pp. 113-123.

[18] J. Lawrence Soske. Theory of Magnetic Method of Applied geophysics with an implication to San Andreas Faults (Doctorate Thesis), Pasadena, California (1935). Pgs. 7-31, 50-55.

[19] D.L Turcotte, and Schubert, Geodynamics: Application of Continuum Physics to Geological problems, John Wiley and Sons, New York, ,(1982). (Plate tectonics- chap 1).

[20] I.J Won, Application of Gauss's method to interpretation of magnetic anomalies of dipping dikes: Geophysics Journals, Vol. 46, (1981). Pgs 211-215. 